\title{
Improving the Dynamic Behavior of Adjacent Buildings with Fluid Viscous Dampers
}

\author{
Solmaz Yaghobzadeh ${ }^{1}$ \\ ${ }^{1}$ Department of Civil Engineering, University of Tabriz Aras International Campus, Iran \\ Correspondence: Solmaz Yaghobzadeh, Department of Civil Engineering, University of Tabriz Aras International \\ Campus, Tabriz, Iran. E-mail: Davoodkamrani@gmail.com
}

Received: April 7, 2016

doi:10.5539/mas.v10n12p245
Accepted: June 18, 2016

Online Published: November 25, 2016

URL: http://dx.doi.org/10.5539/mas.v10n12p245

\begin{abstract}
Explained ways to strengthen structures against lateral dynamic loads can be divided into two broad categories. The first part is the structural systems for controlling seismic displacement and second part is the use of applying systems of control forces. Response mechanism of structures using control systems are improved and greatly reduce the risks of damage caused by earthquakes.

Today the use of these control systems in buildings have been increased and it's important to reduce vibration of structures is felt more than ever. As well as to improve the dynamic behavior of nearby buildings, control systems can be installed between adjacent buildings as activated, semi-active and inactivated systems. The main purpose of this study is the use of control systems in two similar adjacent buildings to reduce the entire system response which will be the analytical study of the impact of viscous dampers to control system performance.

In order to analysis of modeling to improve the dynamic behavior of different adjacent buildings connected with dampers, two models of the original sample will be examined in this article. All examples are different from each other and to elicit response analysis and time history software SAP 2000was used. According to the results the effect of fluid viscous dampers for tall buildings compared shorter building, is less. Also, these dampers for adjacent buildings with different heights than buildings with same height are more effective.
\end{abstract}

Keywords: dynamic behavior, adjacent buildings, viscous dampers

\section{Introduction}

Many buildings that have not been able to withstand lateral loads and have been broken down and reversal reflects the great importance of the protection of buildings against vibrations. In recent years a large number of people in the world lost their lives in the earthquake and large financial losses have been imposed on as well. The recent earthquakes in Iran, as well as in different parts of the world such as Bam 1382, Azerbaijan in 1391, Turkey in 1999 and Taiwan in 1999 showed that the vibration of structures has been very severe and led to the destruction of buildings. So it can be concluded, in structural design, buildings design to withstand dynamic loads is very important to prevent the destruction of structures. Protection and maintenance of buildings with residents and the equipment inside it is a global priority. Structural engineers aim is to develop safe structures to resist against natural disasters.

Explained ways to strengthen structures against lateral dynamic loads can be divided into two broad categories. The first part is the structural systems for controlling seismic displacement and second part is the use of applying systems of control forces. Response mechanism of structures using control systems are improved and greatly reduce the risks of damage caused by earthquakes.

Today the use of these control systems in buildings have been increased and it's important to reduce vibration of structures is felt more than ever. As well as to improve the dynamic behavior of nearby buildings, control systems can be installed between adjacent buildings as activated, semi-active and inactivated systems. Different control methods and systems for the control of adjacent structures against earthquakes have been done by scientists and engineers or are being done. Hasner et al. (1997) in a study examined the benefits of structural control in reducing unwanted vibration in buildings. They also proposed various control systems for this purpose.

Seto (1994) has introduced connecting the adjacent buildings as a practical way to protect and strengthen structures against dynamic loads. He has introduced different strategies for inactivated control systems for tall and 
short buildings.

Gurly et al. (1994) and Sojinio et al (1999) also in some studies have addressed the adjacent high-rise buildings with inactivated systems.

Luque and Debaros (1998) and Zhou et al. (1999) examined the connection of high-rise buildings structure to average height ones. Ying et al (2003) studied a stochastic optimal control system for connected adjacent structures. In their study, control systems and structures under stochastic seismic movements were modeled and with energy control of structure, the seismic response of structure and control system dimensions were reduced. They also conducted a numerical study to estimate the reduction capacity of seismic response in connected adjacent buildings.

Ney et al. (2001) in a study examined the seismic response of two adjacent and connected buildings by hysterical non-linear dampers under various seismic movements and stated that such dampers are fruitful, even if only on a few floors to be installed. Parametric study and sensitivity analysis to find and insertion the optimal number was done.

Hadi and Owz (2009) in a study examined the importance of using fluid viscous dampers to improve the seismic behavior of adjacent structures. They found declines of the last floor displacement, acceleration and shear force response of adjacent structures during seismic stimulation. In their study adjacent structures had been connected in one direction by dampers. Major earthquakes such as Bam, Azerbaijan, Turkey earthquake and others have shown that municipal buildings and buildings are not resistant enough to withstand during earthquake severe shocks. Severe inelastic behavior caused by severe shaking is clearly visible. This inelastic behavior threatens the safety of residents of buildings and facilities and will ultimately lead to the loss of life of many people.

In building constructions, the main purpose is the protection of structures against earthquakes. In recent years, engineers in high-rise buildings have begun to use control systems, such as activated, semi-active and inactivated to reduce seismic response. In buildings with a lot of height, the structures control with this method is difficult. Additionally since high-rise buildings require so much energy, are relatively flexible.

Control of interconnected buildings first time was suggested based on the idea of exertion of force on each other. This idea for the first time was proposed in the past three decades by Klein and Halle (1985). They first offered a semi-activated system, which connect two adjacent buildings with the cables by the ability to loosen and tighten (Klein and Halle, 1985).

Christensen and colleagues in 1999 stressed that the idea of adjacent structures connection has been converted from theory into practice and in Japan and America has been considered by engineers (Krystnsvn et al., 1999).

\section{Inactivated Control Systems}

In these systems, vibration control agent is placed in the proper location of the structure and practically prior to the stimulation of structures is inactive. Hasnr and colleagues noted in 1994 that inactivated control systems taking the energy resulted from dynamic loading. All inactivated control devices have stiffness and damping to dissipate energy and provide the shift limits of buildings to each other.

These systems are characterized by control forces and their fixed specifications. Another advantage of this system is the ability to install again after the earthquake. Song and Dargosh (1997) in a study stated that inactivated control systems, including metallic, fricative, viscoelastic and fluid viscous, massive and regulated fluid dampers. These dampers are installed to strengthen the building against lateral loads (Song and Dargosh, 1997). One of important devices of damper in inactivated control systems is seismic isolators. Varnoteh et al (2007) suggested that the seismic isolator systems can't be used to reduce the displacement of a structure or two adjacent or connected buildings.

Seismic isolators are installed in the foundations of buildings to absorb or reflect some of the energy of earthquake and prevent its transmission to structural elements (Varnoteh et al., 2007). 


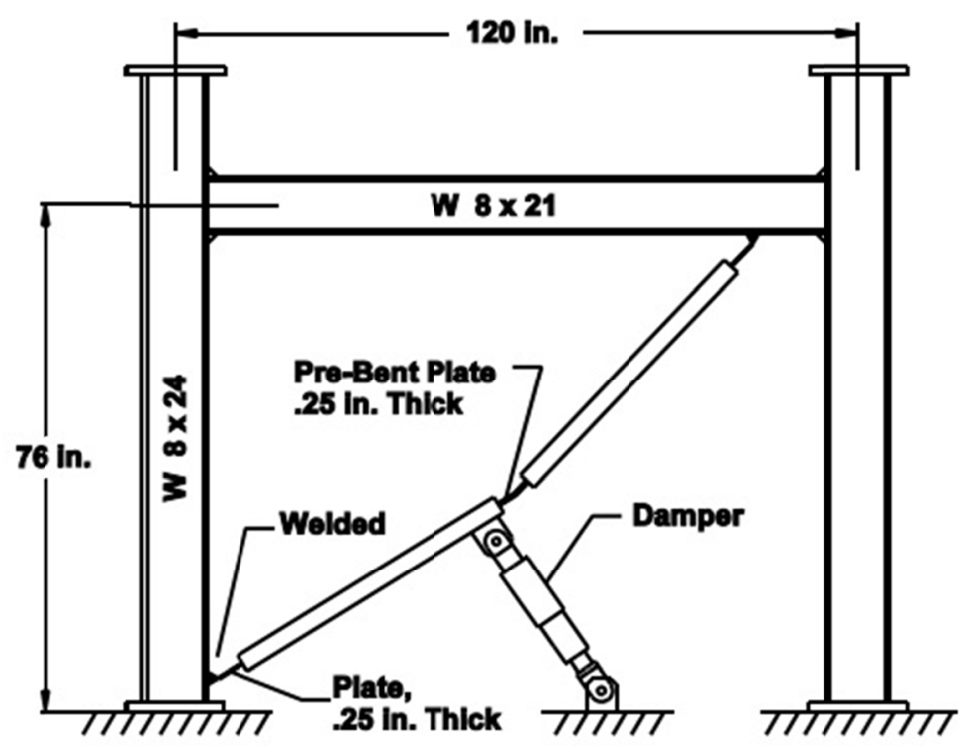

Figure 1. Schematic view of the completed damper (Taylor and Constantine, 1998)

Today the use of fluid viscous dampers in buildings adjacent have been increased greatly (Varnoteh et al., 2007). Descriptions of viscous dampers of inactivated control systems will be provided in Section 2.3.

\section{Fluid Viscous Dampers}

High resistance viscous fluids against the flow, is the basic function of viscous dampers. Deformation speed of a fluid viscous damper is proportional to the applied forces (Taylor and Constantine, 1998).

Fluid viscous dampers act like shock absorbers of vehicles (Varnoteh et al., 2007). Figure 2-5 shows a sample of fluid viscous damper. The dampers are formed with a cylinder containing a fluid, such as oil. Inside these cylinders a piston acts with a number of leaks that is connected to the piston rod. The dampers operate by piston moves inside the valves with viscous fluid damper. The shape and size of the holes inside the piston as well as the viscosity of the fluid used can affect the amount of energy and sustainable energy.

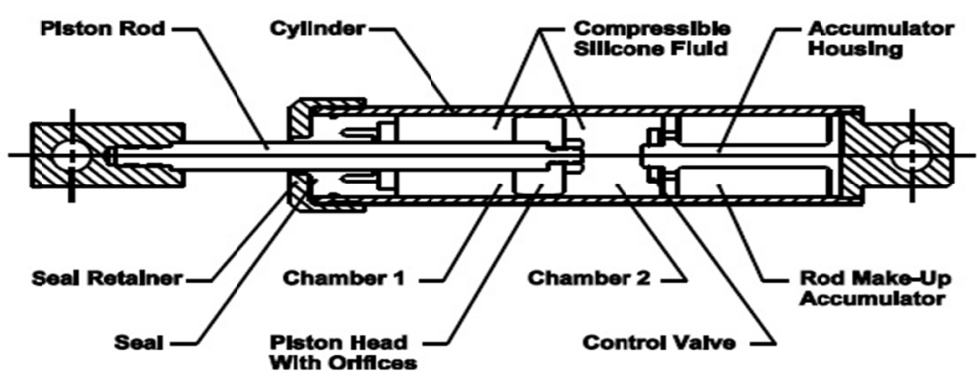

Figure 2. An example of fluid viscous damper (Taylor and Constantine, 1998)

Stresses and deformations of building during applying dynamic load by the dampers are reduced. Dampers with applying opposing forces to structural elements neutralize the inflicted force of them and depreciate it. If the damper not to be used, structural elements, especially columns highly are placed under stress and their stress will be maximum, as well as the displacement of them in earthquake will be high (Varnoteh et al., 2007). By using the damper and during displacement and bending of columns maximum, the maximum damper force will be maximum (Varnoteh et al., 2007).Fluid viscous dampers due to their very appropriate function are preferred to other techniques. To connection the dampers to the building, there are different methods. Fluid dampers connecting in adjacent buildings have changed in recent years. 


\section{Providing Relationships and Equations}

Buildings A and B respectively have $\mathrm{n}+\mathrm{m}$ floor and $\mathrm{n}$ floor (Figure 3). Mass, damping, and shear stiffness for floor $\mathrm{i}$ can be showed as $\mathrm{m}_{\mathrm{i}}, 1, \mathrm{c}_{\mathrm{i}},{ }_{1}$ and $\mathrm{k}_{\mathrm{i}, 1}$ for building $\mathrm{A}$ and $\mathrm{m}_{\mathrm{i}, 2}, \mathrm{c}_{\mathrm{i}}, 2$ and $\mathrm{k}_{\mathrm{i}, 2}$ for building $\mathrm{B}$, respectively. Fluid damper stiffness and damping coefficient on floor $\mathrm{i}$ can be just showed as $\mathrm{k}_{\mathrm{d}, \mathrm{i}}$ and $\mathrm{c}_{\mathrm{d}}, \mathrm{i}$.

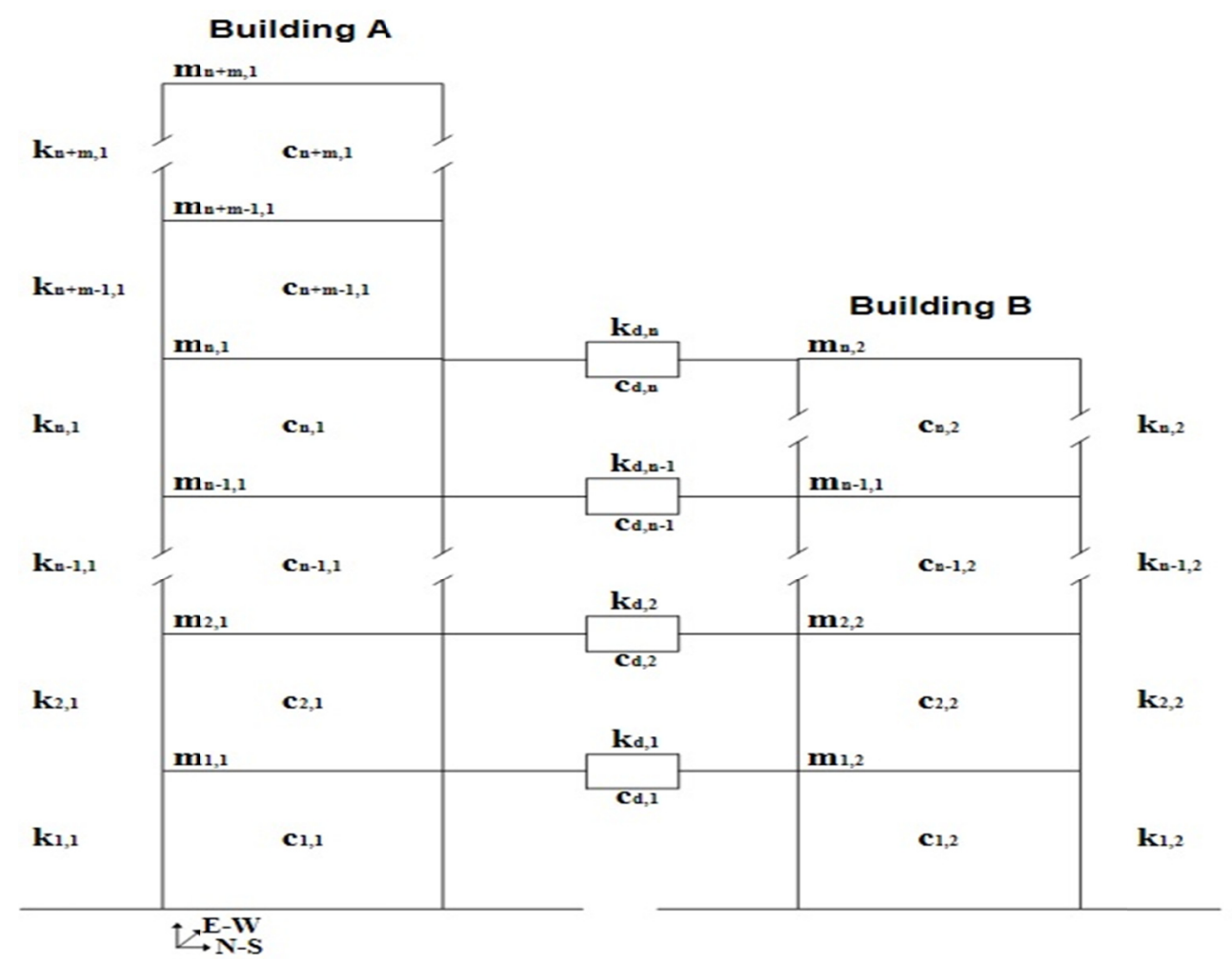

Figure 3. The structural model of connected buildings with dampers

Dynamic model for connected building has $2 n+m$ degrees of freedom. The equation of motion for the system is as follows:

$$
M \ddot{Y}+\left(C+C_{d}\right) \dot{Y}+\left(K+K_{d}\right) Y=-M I \ddot{Y}_{g}
$$

In this equation, $\mathrm{M}, \mathrm{C}$ and $\mathrm{K}$, are mass matrix, damping, and stiffness of adjacent buildings, respectively. $\mathrm{C}_{\mathrm{d}}$ and $\mathrm{K}_{\mathrm{d}}$ are also matrices damping and additional stiffness which being added by fluid viscous damper adding. $\mathrm{Y}$ is the displacement vector to the earth, including displacement of building A on the first floor of $m+n$ and displacement of building B on $\mathrm{n}$ last floor. Here $\mathrm{I}$ is the identity matrix. $\ddot{\mathrm{Y}}_{\mathrm{g}}$ is earthquake acceleration in foundations of the adjacent connected buildings.

\section{Studied Buildings Samples}

This study examines the displacement of adjacent buildings from an analytical perspective with taking into account the effects of fluid viscous dampers. In current study, a linear model for the adjacent structures considering geometric linearity and materials has been developed. A limited three-dimensional elements model has been defined and a linear time history analysis has been performed to investigate the seismic behavior of structures under study. In this thesis, the software SAP 2000 has been used for linear time history analysis of structures. SAP 2000 software for modeling the effects of fluid viscous dampers can be used and linear parameters of fluid viscous dampers are used. In the software, the equations of motion using Newmark stepwise method and assuming a linear change of acceleration in a small timeframe are solved.

Recorded earthquakes with the same period have been used to examine fluid viscous dampers behavior. History of 1940 El Centro, 1994 Norserych, 1995 Koobeh and 1989 Loma Prieta for dynamic analysis of studied samples in this thesis will be used. Maximum ground acceleration during EL Centro earthquakes, Kobe, North Rich and Loma Prieta are g0.3495, g0.8337, g0.8428 and is g0.47 respectively (g acceleration due to gravity). 
These two earthquakes were 7.1 and 6.8 on the Richter scale. The duration of these earthquakes was 60 seconds which were recorded in the 3000 time intervals of 0.02 second. Without changing the total time, time intervals can be changed to change the dominant frequency of ground motion. For example, dominant conditions in the presence of loose soil can be revealed by increasing the time interval, and strong or rocky soil condition happens by reducing the time interval $(\Delta \mathrm{t})$. However, in this thesis, interval $=0.02 \Delta \mathrm{t}$ seconds has been selected. Time history responses including horizontal displacements, velocity, acceleration and internal forces of all nodes and structural members in all degrees of freedom have been calculated.

To improve the dynamic behavior of different adjacent connected buildings with dampers, two models of the original sample is examined in this article. All examples are different from each other. Example 1 will be two 5 -storey buildings connected together with a damper which has been shown in Figure 4. Example 2 is a 10 -storey building with fluid viscous damper has been connected to a 5 -storey building. The binding way is shown in Fig. 4-B. In order to further review of the effectiveness of fluid viscous dampers, the examples of referred adjacent buildings for two modes with different stiffness and the same stiffness are examined. Two scenarios will be examined, the first scenario indicating a mode in which two adjacent buildings have different stiffness and in the second scenario connected building are posited with the same stiffness. The first scenario is specified by a and second by $b$. For example, example 1 a will be two adjacent 5 -storey buildings with different stiffness and example $1 \mathrm{~b}$ two will be a two adjacent 5 -storey buildings with the same stiffness.

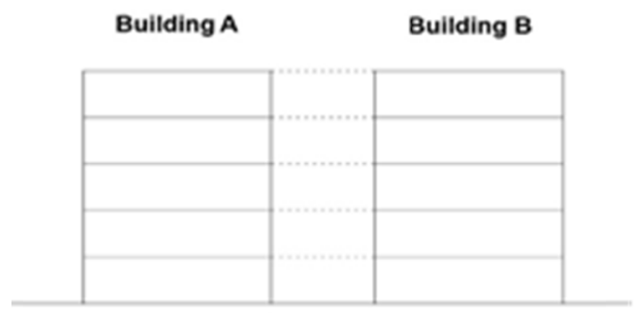

a

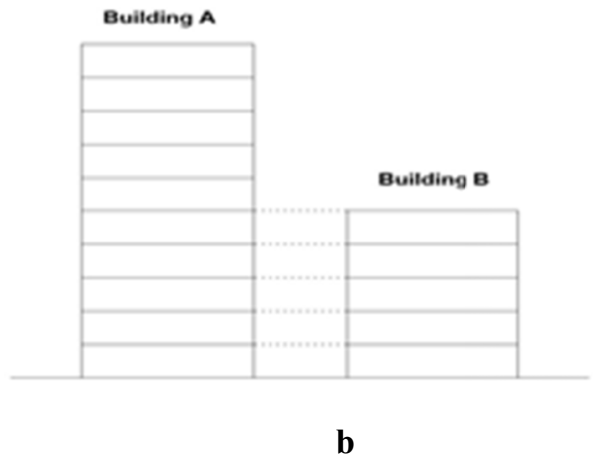

b

Figure 4. The schematic view of adjacent buildings in four main examples

In this paper, two fluid viscous dampers that will be shown with D1 and D2 initials will be used. Xu and colleagues (1999) in a study determined the amount of damping coefficient for adjacent buildings about $1 \times 10^{6} \mathrm{~N} \times \mathrm{s} / \mathrm{m}$. In this paper, the damping coefficient in two basic models, are considered $\mathrm{c}_{\mathrm{d}}=0.25 \times$ $10^{6} \mathrm{~N} \times \mathrm{s} / \mathrm{m}$ and $\mathrm{c}_{\mathrm{d}}=0.85 \times 10^{6} \mathrm{~N} \times \mathrm{s} / \mathrm{m}$, respectively.

Table 1 shows the size of rows and columns in the mentioned sample buildings.

Table 1. The dimensions of the rows and columns in adjacent buildings on both models

\begin{tabular}{ccccccc}
\hline \multicolumn{2}{c}{ Building B } & \multicolumn{2}{c}{ Building A } & Example \\
\hline $\begin{array}{c}\text { Row } \\
\text { dimensions } \\
(\mathrm{mm})\end{array}$ & $\begin{array}{c}\text { row } \\
\text { width }(\mathrm{mm})\end{array}$ & row height $(\mathrm{mm})$ & $\begin{array}{c}\text { Row } \\
\text { dimensions } \\
(\mathrm{mm})\end{array}$ & $\begin{array}{c}\text { row } \\
\text { width }(\mathrm{mm})\end{array}$ & $\begin{array}{c}\text { row height } \\
(\mathrm{mm})\end{array}$ & number \\
\hline $500 \times 300$ & 250 & 500 & $600 \times 300$ & 250 & 600 & $1 \mathrm{a}$ \\
$500 \times 300$ & 250 & 500 & $500 \times 300$ & 250 & 500 & $1 \mathrm{~b}$ \\
$500 \times 300$ & 250 & 500 & $600 \times 300$ & 250 & 600 & $2 \mathrm{a}$ \\
$500 \times 300$ & 250 & 500 & $500 \times 300$ & 250 & 500 & $2 \mathrm{~b}$ \\
$600 \times 300$ & 300 & 500 & $700 \times 300$ & 300 & 600 & $3 \mathrm{a}$ \\
$600 \times 300$ & 300 & 500 & $600 \times 300$ & 300 & 500 & $3 \mathrm{~b}$ \\
$600 \times 300$ & 300 & 500 & $700 \times 300$ & 300 & 600 & $4 \mathrm{a}$ \\
$600 \times 300$ & 300 & 500 & $600 \times 300$ & 300 & 500 & $4 \mathrm{~b}$ \\
\hline
\end{tabular}

Figure 5. show schematic plan of rows and columns in the adjacent buildings and the installation place of dampers for both models 


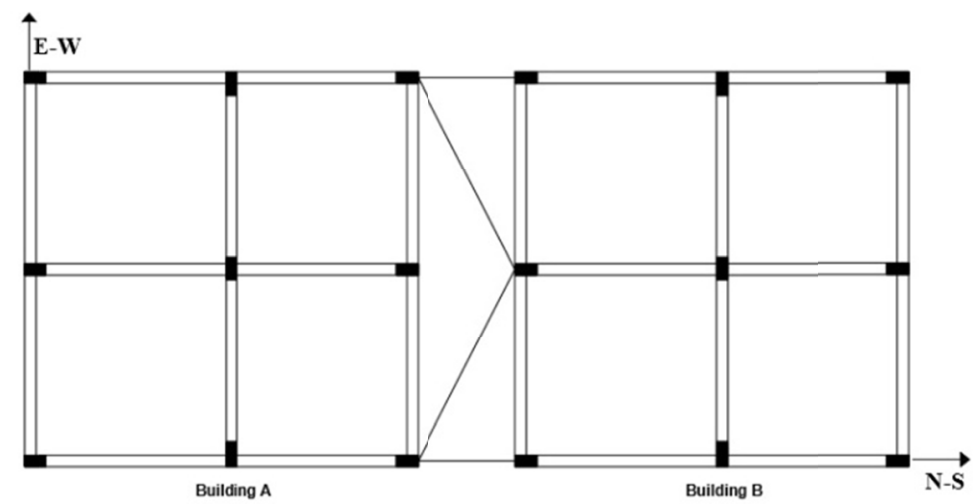

Figure 5. Schematic diagram of rows and columns plan in the connected adjacent buildings for both models

\section{Frequency Results and Time Domain}

\subsection{The Results Frequency Division}

In the first part of the analysis of adjacent buildings response spectrum of buildings were used for the analysis. For this purpose, EL Centro in 1940, Norserych 1994, Kobe 1995 and 1989 Loma Prieta earthquakes have been used. In this section displacement charts - the frequency and acceleration - frequency is presented. Two types of damper (D1, D2) with different damping coefficients have been used in this model. The spectral density of not connected buildings, two natural frequency of building A can be defined in milestones for the related earthquake. For example, in Loma Prieta earthquake in 1989 in the north - south, the natural frequency has been defined 6.82 and $3.2 \mathrm{~Hz}$. The third natural frequency also was defined higher than $30 \mathrm{~Hz}$ for Building A. Three natural frequencies of building B, were determined 2.69, 6.67 and $30 \mathrm{~Hz}$, respectively. It can be easily seen in Figure 6 that by increasing the natural frequency of the buildings the maximum displacement of not connected buildings decreases.

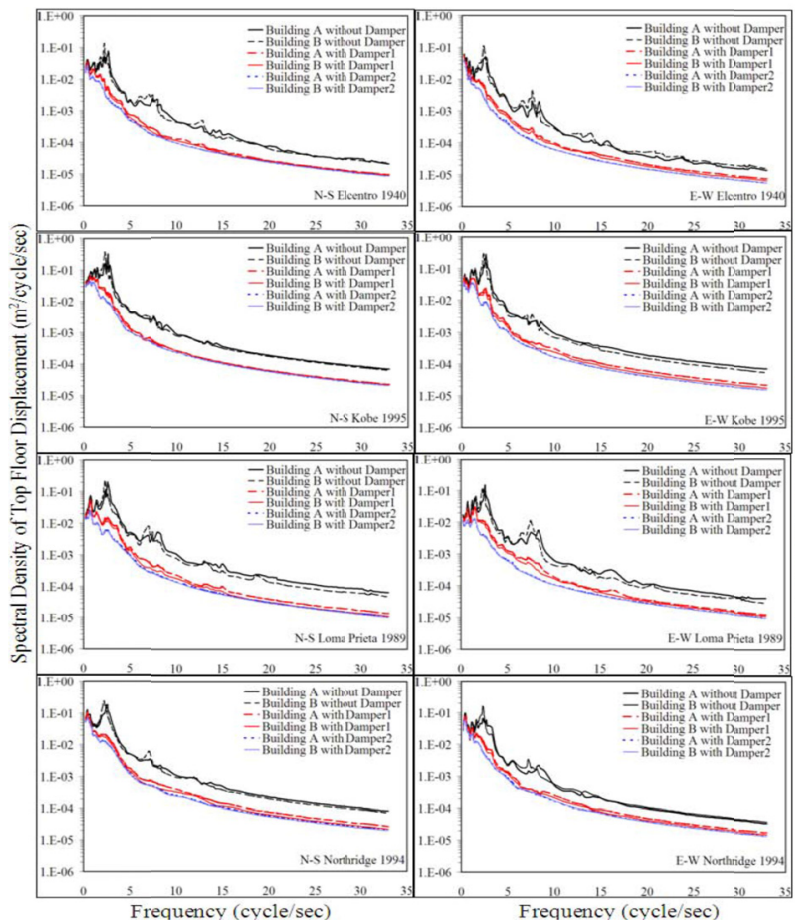

A

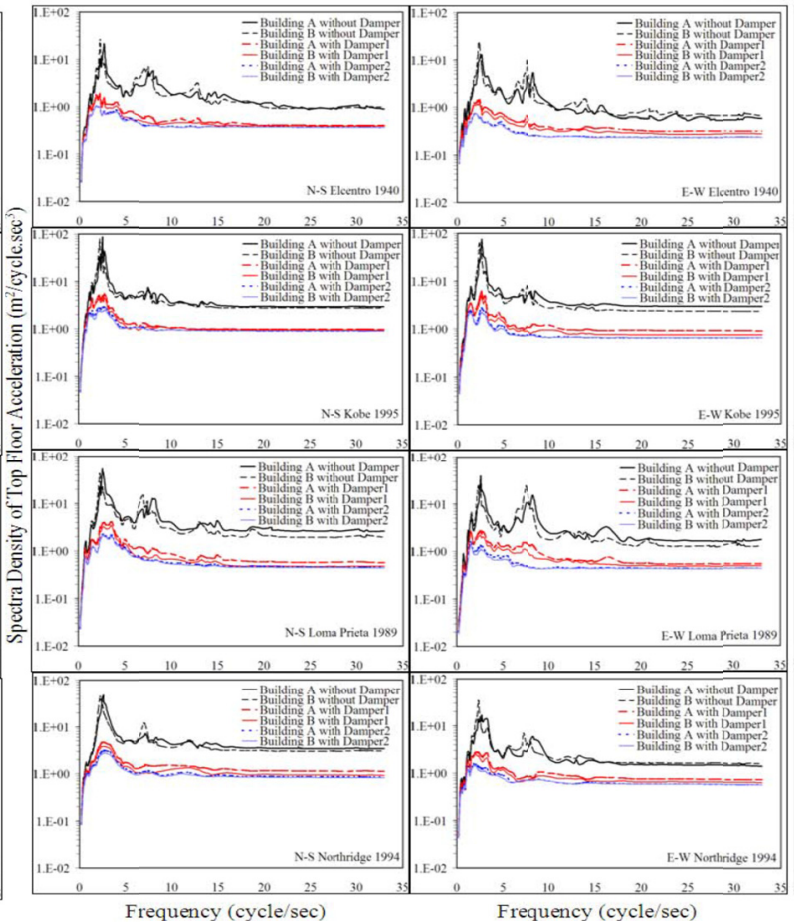

B

Figure 6. A Spectral density of acceleration of the top floor of two connected buildings, for example, 1a in two directions; B Spectral density of displacement of the top floor of two connected buildings, for example 1a in two directions 
For example 1b, spectral density of displacement of the top floor of Building A and Building B without damper due to having the same height and the same shear stiffness (Figure 7)

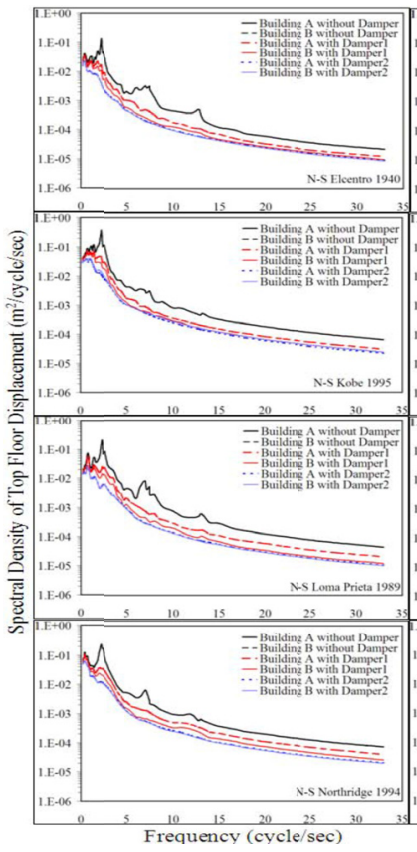

A

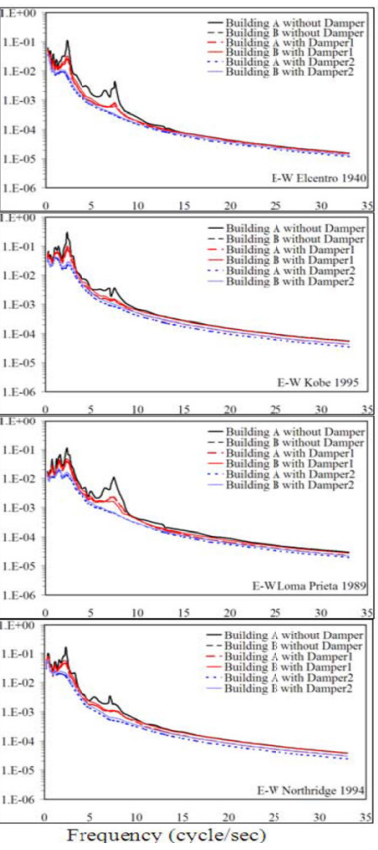

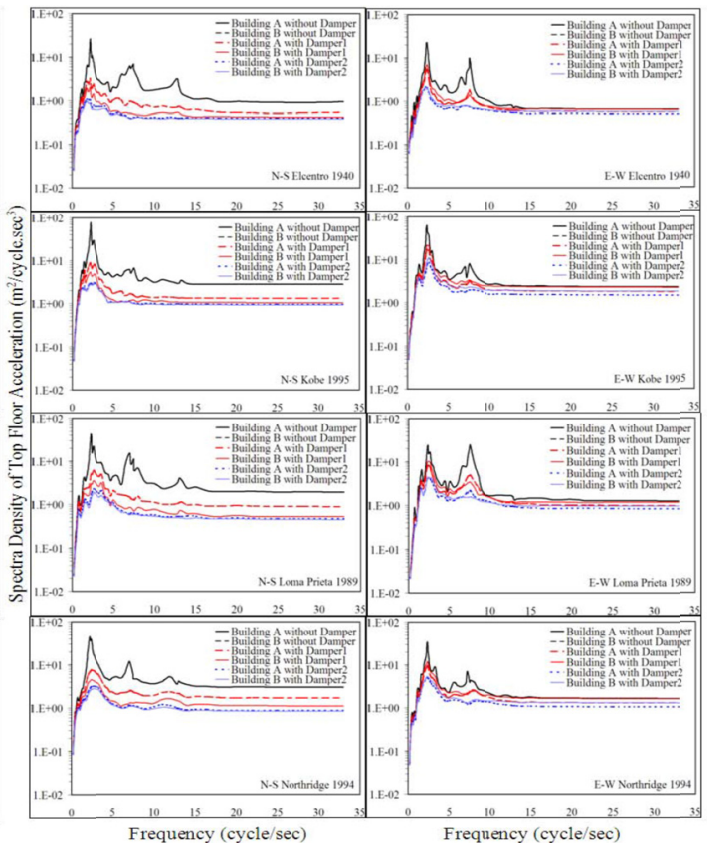

B

Figure 7. A Spectral density of acceleration of the top floor of two connected buildings, for example b1 in two directions; B Spectral density of displacement of the top floor of two connected buildings, for example b1 in two directions

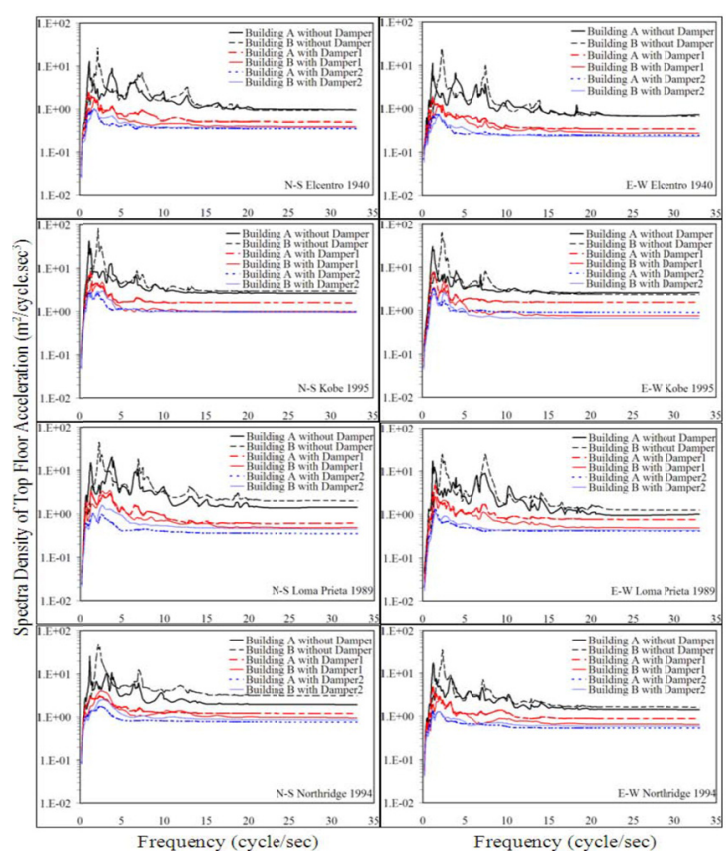

A

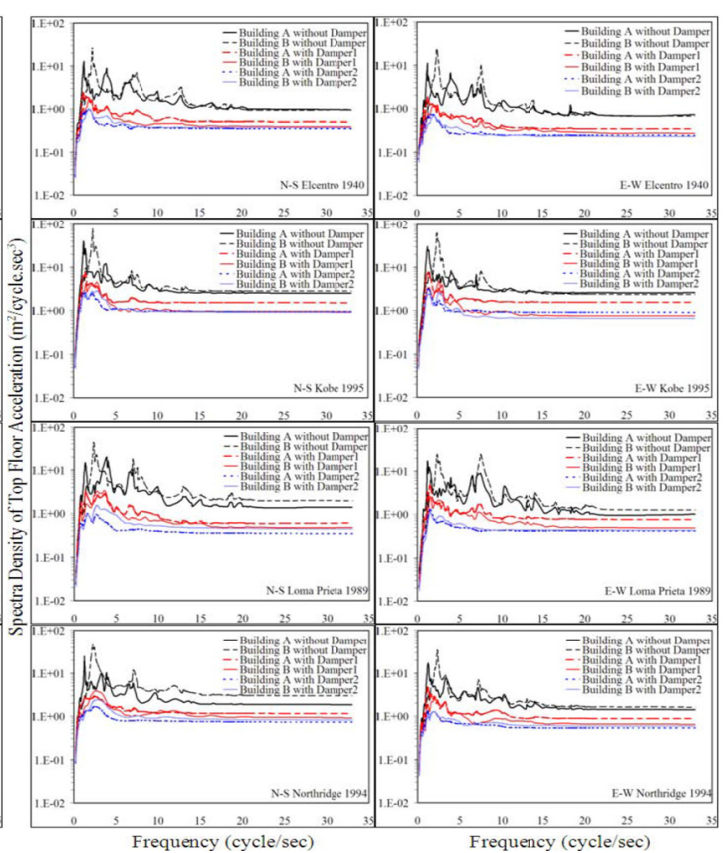

B

Figure 8. A Time history of displacement of the top floor of adjacent buildings, for example 1a in the north-south;

B Time history of displacement of the top floor of adjacent buildings, for example 1a in the East - West

\subsection{The Results of Time Domain}

In the second part of computer analysis in this paper, displacement charts - time and acceleration - extraction time from SAP 2000 software is presented. In this section displacement charts - time and acceleration - time for 
all examples will be presented individually to review the effectiveness of the connecting dampers. To examine the displacements, connected buildings in all examples by considering earth motion and time history of acceleration of four earthquakes will be examined. Also, to examine shear force, buildings under ground motion during earthquakes and time history of earthquake acceleration of mind will be considered.

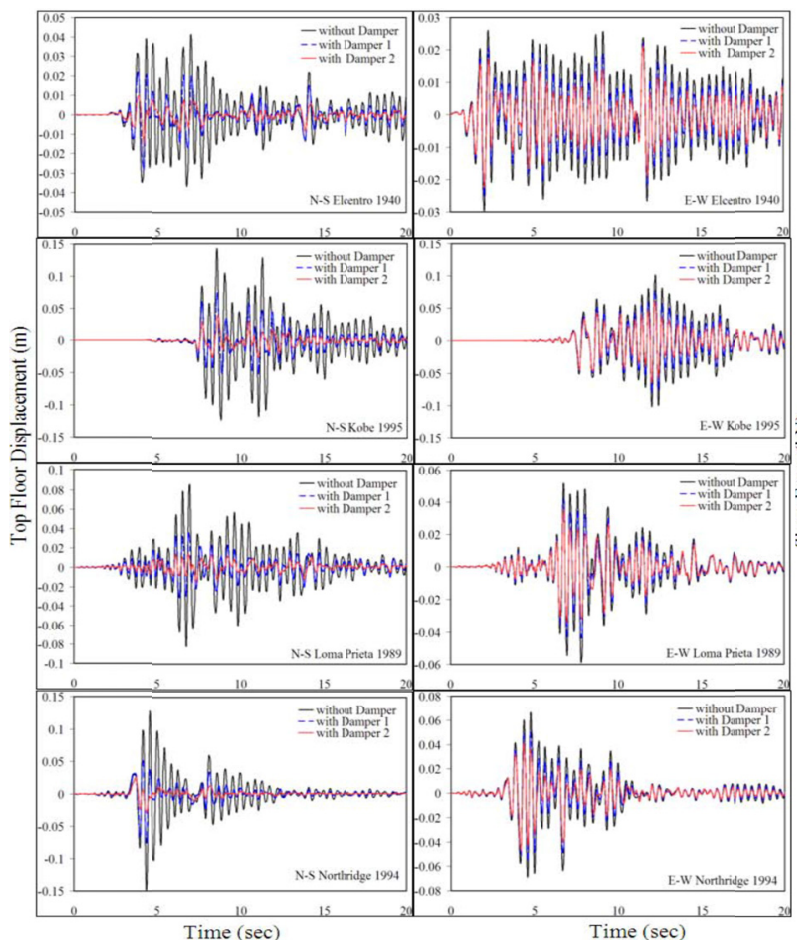

A

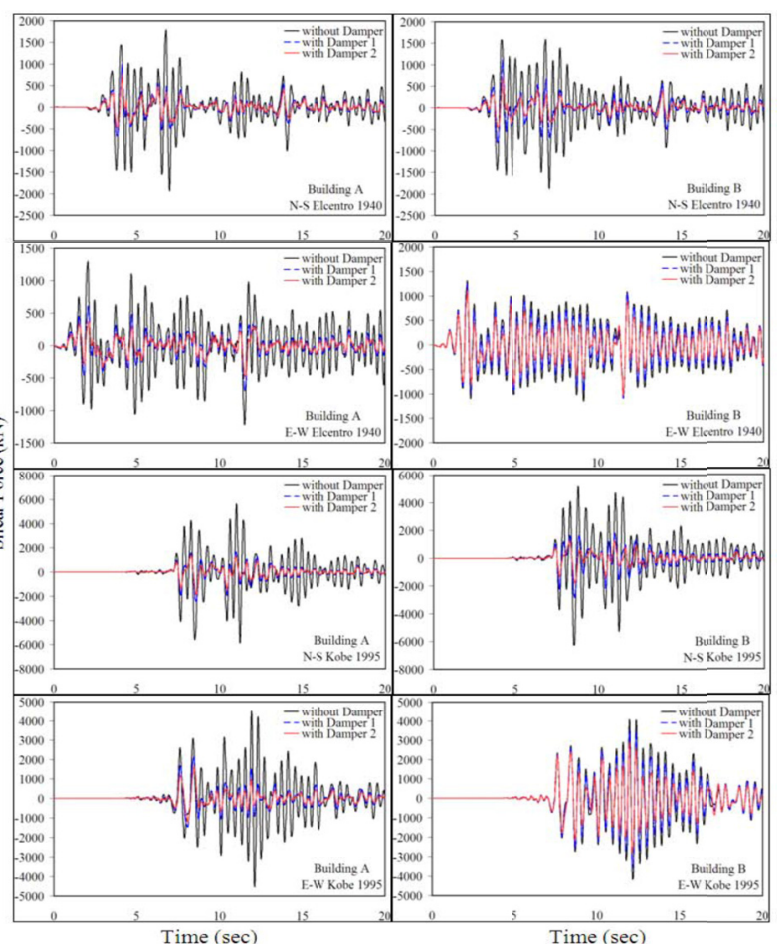

B

Figure 9. A Shear force - time chart in North - South and East - West, for example 1a; B Time history of displacement of the top floor of adjacent buildings in two directions for example $1 \mathrm{~b}$

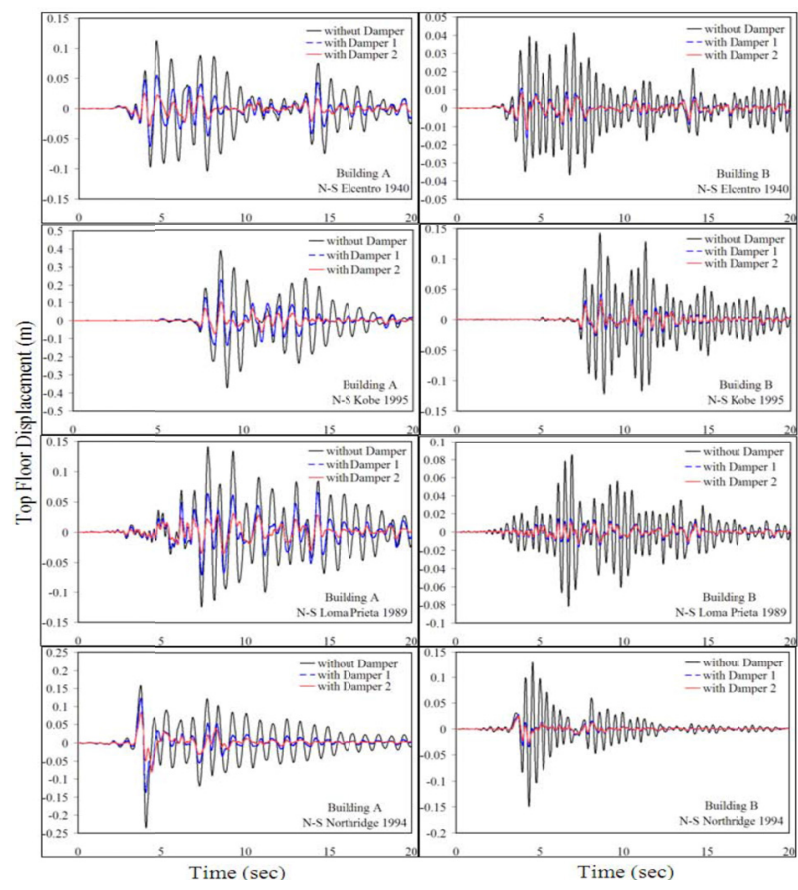

A

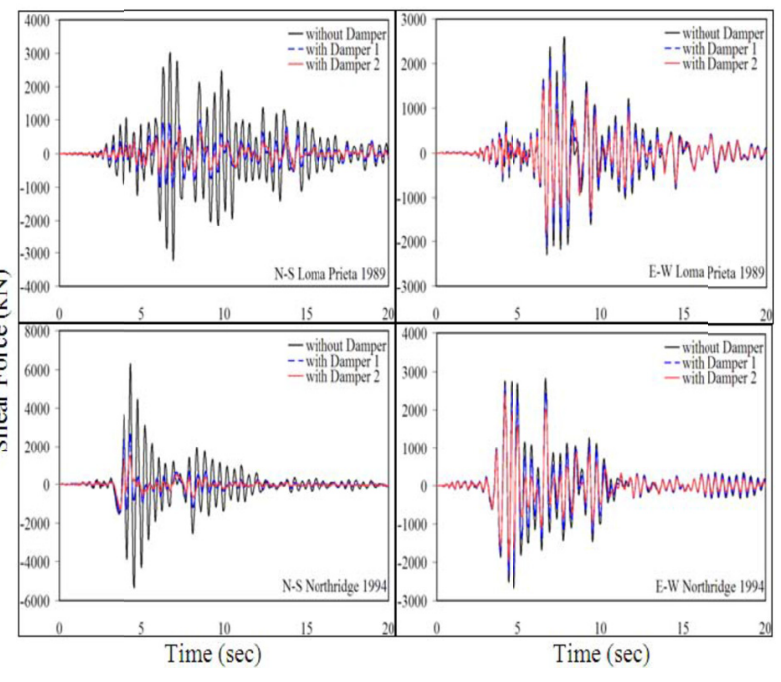

B

Figure 10. A Shear force - time chart of adjacent buildings for example 1b; B Time history of displacement of the top floor of adjacent buildings in north-south for example 2a 


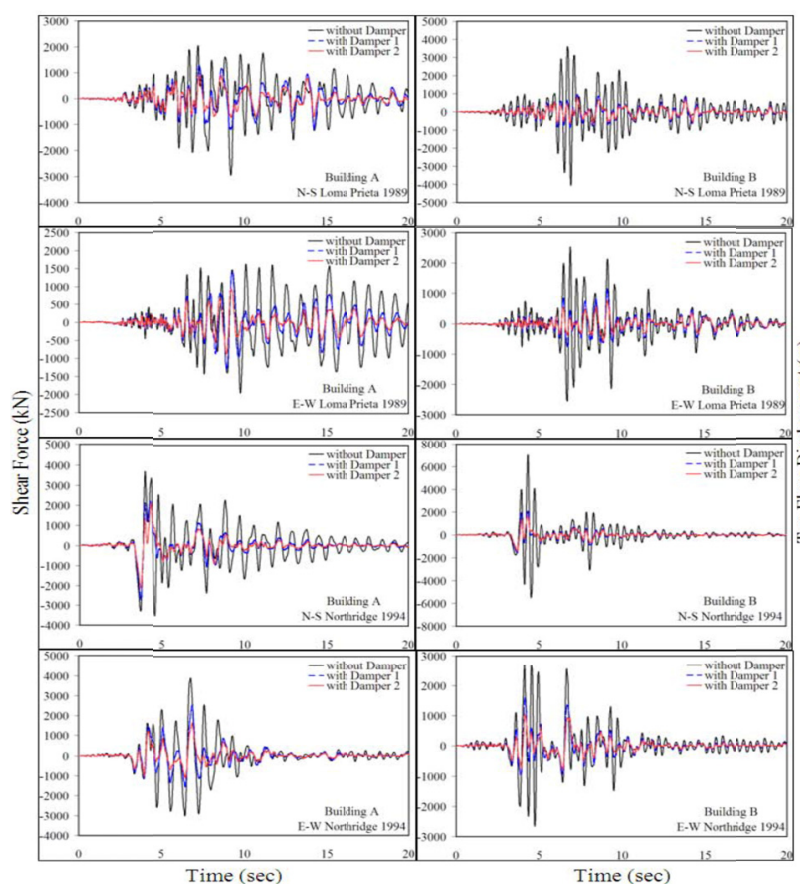

A

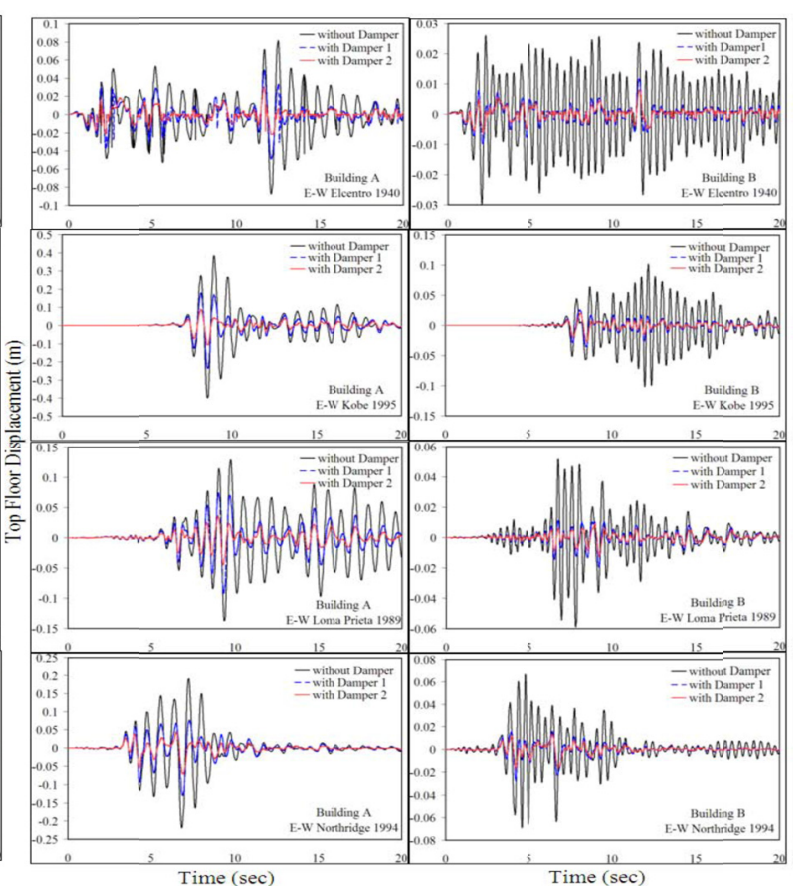

B

Figure 11. A Time history of displacement of the top floor of adjacent buildings in East-West for example 2a; B Shear force - time chart of adjacent buildings for example $2 \mathrm{a}$

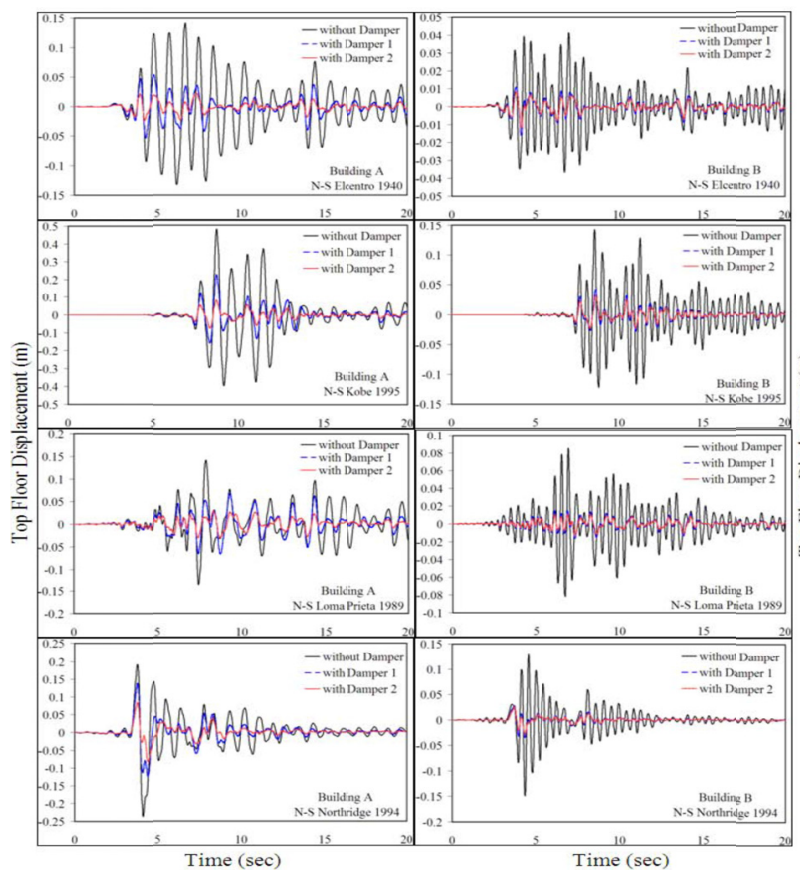

A

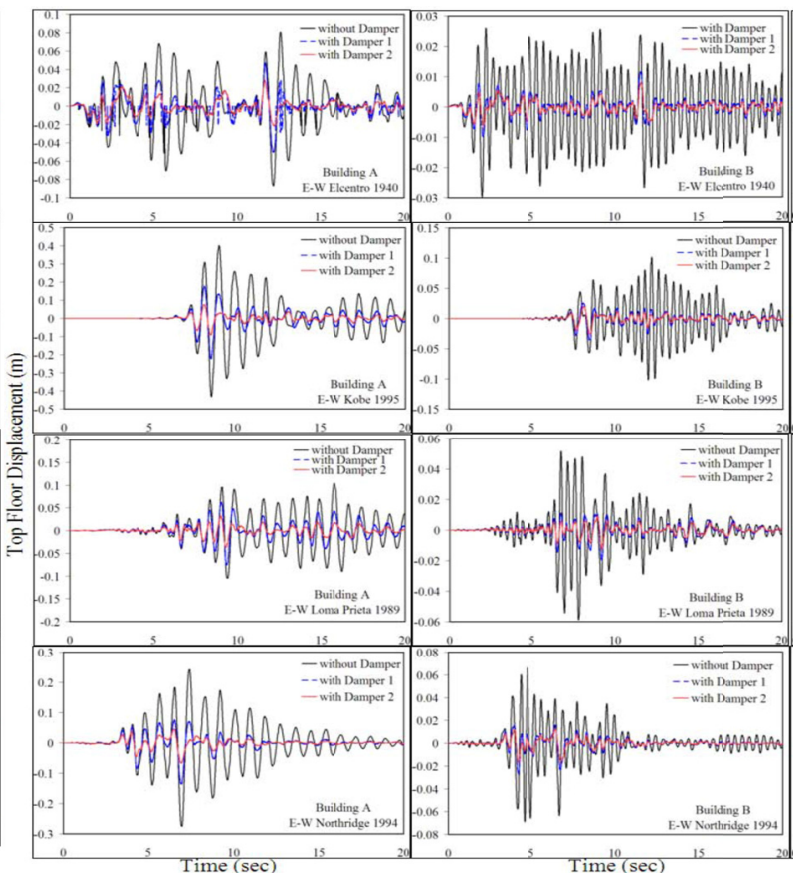

B

Figure 12. A Time history of displacement of the top floor of adjacent buildings in North-South for example 2b;

B Time history of displacement of the top floor of adjacent buildings in East-West for example $2 b$ 


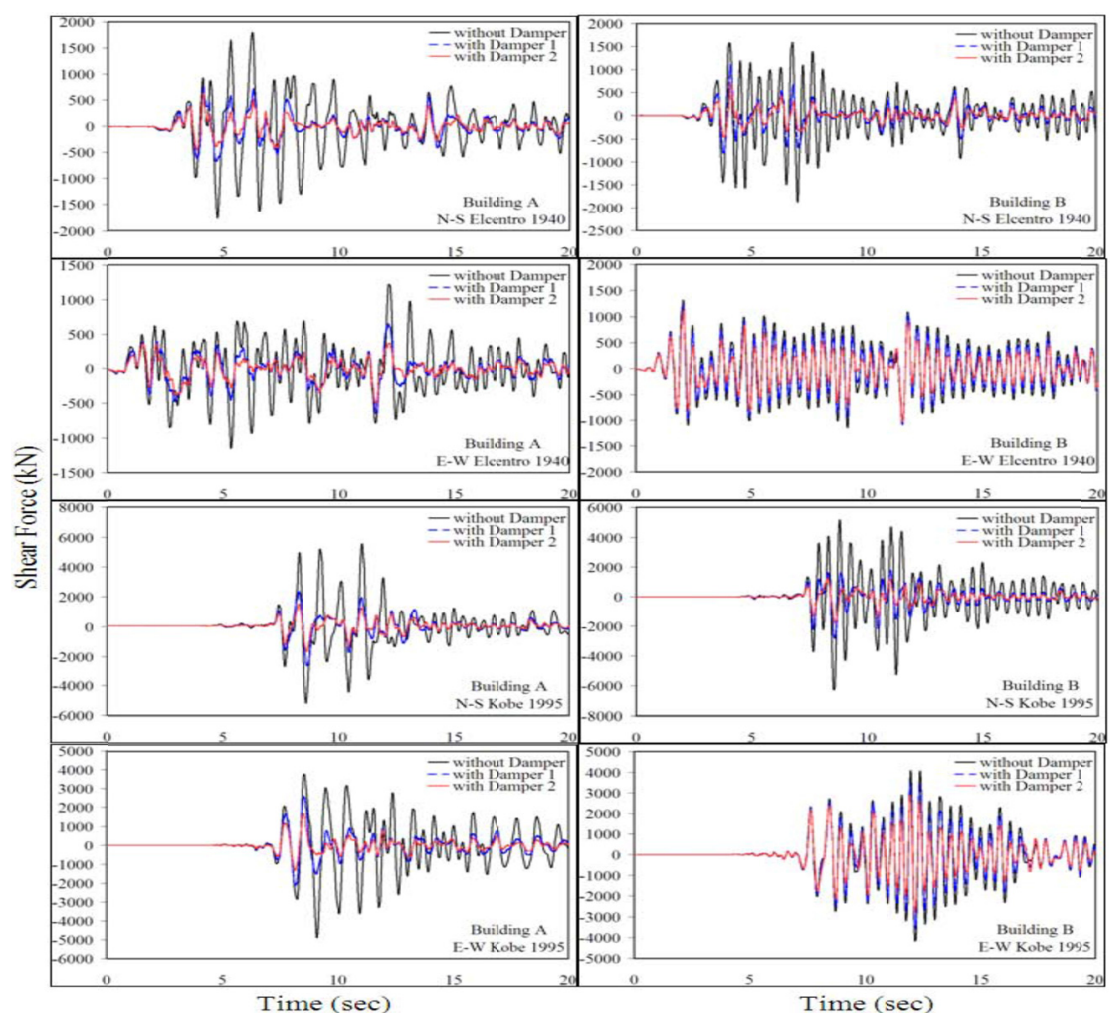

Figure 13. Acceleration - time chart of adjacent buildings in two directions, for example $2 b$

\section{Conclusion}

In this paper time changes of floor displacements and responses of basic cutting in all floors of two connected buildings with fluid viscous damper, with optimal damping coefficient and stiffness coefficient of damping were studied. As clearly the important role of effectiveness of the dampers in the earthquake response controlling was seen in two adjacent buildings. According to the results the effects of fluid viscous dampers for tall buildings than shorter buildings is less. Also these dampers for adjacent buildings with different heights than buildings with same height are more effective. At first charts of frequency domain were presented based on spectral density of displacement and acceleration functions. In example 2 it was clearly seen that using damper for shorter building B has better performance than using it in taller building A. It was observed that connecting dampers for shorter buildings were more useful than high-rise buildings. In model $2 b$ it was observed that while the buildings had different dynamic characteristics, peak points of charts slowly were changing. Then the time domain using time history charts and base shear force and displacement for each of the four examples were presented. In example 1 it was observed fluctuations of displacements were reduced significantly in the north and south. In the East - West direction of connected buildings and not connected buildings showed a different extent in reducing displacement. The maximum reduction was observed in the displacement of the top floor in Example 2 at a rate of 50 percent.

\section{References}

Hadi, M. N. S., \& Uz, M. E. (2009). Improving the dynamic behaviour of adjacent buildings by connecting them with fluid viscous dampers, 2nd International Conference on Computational Methods in Structural Dynamics and Earthquake Engineering, Island of Rhodes, Greece, 280.

Housner, G. W., Bergman, L. A., Caughey, T. K., Chassiakos, A. G., Claus, R. O., Masri, S. F., Skelton, R. E., Soong, T. T., Spencer, B. F., \& Yao, J. T. P. (1997). Structural control: Past, present, and future. Journal of Engineering Mechanics, 123(9), 897-971.

Housner, G. W., Soong, T. T., \& Masri, S. F. (1994) Second generation of active structural control in civil engineering, Proceedings of the First World Conference on Structural Control, Pasadena, California.

Kim, J., Ryu, J., \& Chung, L. (2006). Seismic performance of structures connected by viscoelastic dampers. Engineering Structures, 28(2), 183-195. 
Richard, E. C., Spencer, B. F., Erik, A. J., \& Seto, K. (2006). Coupled building control considering the effects of building/connector configuration. Journal of Structural Engineering, 132(6), 853-863.

Seto, K. (1994). Vibration control method for flexible structures arranged in parallel. Proc. First World Conference on Structural Control, Los Angeles, FP3-62-71.

Seto, K., \& Mitsuta, S. (1992). Active vibration control of structures arranged in parallel. Proceedings of the First International Conference on Motion and Vibration Control, Japan, 146-151.

Xu, Y. L., He, Q., \& Ko, J. M. (1999). Dynamic response of damper-connected adjacent buildings under earthquake excitation. Engineering Structures, 21(2), 135-148.

Zhu, H. P., \& Xu, Y. L. (2005). Optimum parameters of maxwell model-defined dampers used to link adjacent structures. Journal of Sound and Vibration, 279(1-2).

\section{Copyrights}

Copyright for this article is retained by the author(s), with first publication rights granted to the journal.

This is an open-access article distributed under the terms and conditions of the Creative Commons Attribution license (http://creativecommons.org/licenses/by/4.0/). 